\title{
ADAPTING CROP VARIETIES TO ENVIRONMENTS AND CLIENTS THROUGH DECENTRALIZED - PARTICIPATORY APPROACH
}

\author{
M.T.K.Gunasekare ${ }^{1}$
}

\begin{abstract}
Since 1990s, participatory approaches have became a driving force for agricultural research and rural development. The participatory approach in crop improvement involves the client-farmer in the cultivar selection or breeding and highly appropriate for increasing food security and improving livelihoods of subsistence farmers in developing countries. This has developed over the past decades as an alternative and complementary breeding approach to formal plant breeding to effectively address the needs of the farmers, especially in marginal or resource poor areas. In pursuit of this concept, this paper discusses the trends, advantages and challenges in this approach highlighting the contemporary evidence of success case studies commissioned by various authorities worldwide. While successful experiences are evident, the potential of such applications are still to be explored. Among the key challenges to the approach, this article pays attentions especially to technical, economic and institutional challenges that need to be overcome to integrate end-users based participatory approaches into the formal plant breeding systems. The paper concludes by describing synergies that can potentially be achieved by linking centralized and decentralized plant breeding models over biotechnological methods.
\end{abstract}

Key words: Formal plant breeding, Participatory plant breeding, Participatory Vareital Selection, marginal environments, decentralized testing, modern varieties

\section{INTRODUCTION}

Crop improvement plays an important role in the development and strengthening of local agricultural systems. The Green Revolution based on introduction of improved varieties with high yield potential, together with technological packages (inorganic fertilizer, pesticides, irrigation etc.) have greatly contributed to the increase in agricultural production in several regions worldwide.

United Nations projections estimate that the world population will continue to grow from the current 6 billion to about 10 billion by 2050 (FAO, 1996). The increase in population and subsequent rise in the demand for agricultural products are expected to be greater in regions where the production is already insufficient, particularly in south Asia and sub-Saharan Africa (Pinstrup-Andersen et al., 1999). The necessary increase in agricultural production represents a huge challenge to the local farming systems and must come mainly from increased yield per unit area, given the limited scope for expanding cultivated land worldwide.

The present approach to agricultural research and development however, is to improve crop, and produce food of quality for all, while reducing environmental degradation and depletion of natural resources base and conserving agricultural diversity. In addition, the priority has now become not just sustainable agriculture, but sustainable livelihoods based on agriculture too. If the modern agriculture to be sustainable, it is expected to contribute towards these goals. 


\section{DISCUSSION}

\section{Farmers' adoption and perception of modern varieties}

Since the first modern varieties (MVs) were released during the late 1960 s and early 1970s, the area planted with MVs has continued to expand. While it is clear that MVs developed through plant breeding programs (the characters of MVs are determined by the objectives of breeders) have brought benefits to millions of producers and consumers, over time, the adoption of MVs has lagged in some areas, including many "marginal environments" (Almekinder \& Louwaars, 1999). "Marginal environments" are defined as areas where agriculture is dominated by variation in agro-ecological and socioeconomic conditions, resulting in complex stress and high production risk or low production potential. Among the factors that have contributed for slow spread of MVs into marginal environments has been the unsuitability of many MVs for specialized production and consumption requirements of people who live in these environments, especially the resource poor-farmers (Elings et al., 2001).

It is commonly assumed that farmers in high potential production systems (HPPSs) have much better access to modern technologies than in marginal environments. In many instances, plant breeding has been beneficial to farmers who enjoy favorable environments or those who could profitably modify their environment to suit new cultivars, especially the MVs. These constraints effectively put the MVs beyond the reach of millions of small-scale/ subsistence farmers who cannot afford the high-priced inputs to get the desired output (Morris \& Bellon,
2004). Hence, it has been realized that further expansion of this high-input model of agriculture would not be sustainable, due to the high cost entailed and the negative impact on natural resources (Conway, 1998; Singh, 2000).

\section{Limitations in formal plant breeding systems}

Despite many advantages towards contributing to crop variety development, the formal or conventional plant breeding (FPB) programs also have some shortcomings.

In conventional crop improvement process, which is highly centralized, researchers make all decisions in breeding varieties and verifying their performances. Most breeding programs identify a core set of priority traits (by the scientists) and work to incorporate those traits into the new varieties. The high-yielding varieties developed by the formal research system or FPB are often high-maintenance varieties and have largely been suitable for resource rich and HPPSs. For many farmers such conditions simply do not exist, and as a result they obtain poor results from high-tech varieties offered by the formal research systems. Many of these farmers reject the plant breeders' offerings simply because they were not designed for marginal farmlands; they meet neither the farmer's needs nor local preferences (Almekinders \& Louwaars, 1999). As a result, old varieties still dominate cultivation in those marginal environments, suggesting that farmers are failing to benefit from modern plant breeding products.

In addition, in the varietal evaluation process, after conducting on-station evaluation (often under optimum input 
conditions), better varieties are identified by the breeder/researcher and made them available for the farmers to test their preferences using only a limited number of varieties merely selected to meet the objectives of the breeder. As a result only few "best" varieties are finally developed and disseminated as a blanket recommendation in response to the varied needs of farmers. This is mainly because national plant breeding programs do not always have sufficient resources to do extensive multilocation testing of varieties, covering all possible variable environments. Hence, this kind of a formal approach poorly addressed the actual needs and preferences of farmers since they only had the options to accept or reject a few finished crop varieties at a very later stage in the crop improvement program. This so-called cultivar development work is justified when a crop is grown in large, ecologically homogenous production environments. Although it may be possible to overcome some of the related problems by conducting on-farm varietal testing, that also tends to be very resource intensive, especially in developing country setting. For this reason, most plant breeding programs base their selection decisions on data generated through on-station trials. This can lead to problems, because research has shown that varieties often perform differently under farmers' management practices than they do under researchers' management practices (Almerkinders \& Louwaars, 1999).

Faced with the evidence that MVs developed for favorable production conditions have not always diffused readily into marginal environments, plant breeders started searching strategies to overcome the problems related to varietal development. These issues forced the scientists to rethink and develop a new paradigm that is need-oriented and address diverse socio-economic conditions, production environments and management practices.

\section{The emerging local approach to plant breeding}

In an effort to overcome some of the limitations in formal traditional approach to plant genetic improvement, there is a growing recognition and interest in farmer participatory approaches in response to the challenge of making agriculture more sustainable (Witcombe et al., 1996). Although the social distance of scientists from farmers varies from crop to crop, there is a possibility of considering farmers as partners in crop improvement programs from the initial stages of breeding and selections (Witcombe, 1996).

There are many variants of farmer participatory approaches in crop improvement. These approaches based on the local crop improvement that benefit from contribution by both plant breeder and farmer (Soleri et al., 2000). This can potentially result in varieties adapted to the needs of farmers with low resources in highly stress- prone environments, and lead to enhanced on-farm (in-situ) conservation of crop genetic resources (Almekinders \& Louwaars, 1999).

\section{Definitions and Strategies}

The lack of consensus about terminology is common when a new science is at its early stages, and Participatory Plant Breeding (PPB) is no exception (Sperling et al., 2001). Terms commonly used include, Informal Research \& Development (IRD); Collaborative Plant Breeding (CPB); Farmer Participatory Breeding 
(FPB); and Participatory Crop Improvement (PCI). According to Witcombe et al., (1996), PCI can be categorized into participatory varietal selection (PVS) and participatory plant breeding (PPB); farmer selection of finished or near-finished varieties is known as PVS, while farmer selection with unfinished material with a high degree of genetic variability is know as PPB. The degree of farmer participation is another dimension for classifying PPB (Sperling et al., 2001). All such terminologies presently use describe broadly the same activities of multifaceted technical and organizational collaboration in plant breeding by scientists and users of their results (Sperling et al., 2001). Moreover, the term PPB does not refer to a single, well defined method for plant genetic improvement; rather, it refers to a set of breeding methods characterized by many different potential forms of interaction between farmers and breeders.

PCI concept builds on the recognition of farmers' capacity to select what best fits for their environment and the fundamental rationale for the approaches is that joint effort can deliver more than when each actor work alone (Witcombe et al., 1996). It does not suggest that this approach is an alternative or complete substitute for conventional on-station and inlaboratory agricultural research. The essential advantage of PCI over conventional breeding is that it involves farmers in developing, adapting and adopting new varieties; setting breeding goals according to their requirements. Farmers become increasingly involved in the generation of technology rather than being simple recipients of new agricultural technology.
Rationale for PCI- Farmers' agendas first

According to Weltzien et al., (2000), PCI is expected to produce more benefits than the formal or conventional crop improvement models in situation where a highly centralized approach is inappropriate. It is also evident that PCI is the only possible approach to breed crops grown in unfavorable conditions or remote regions, in areas not large enough to justify the interest of large breeding programs, and to breed for minor crops neglected by both private and public plant-breeding programs (Ceccarelli, et al, 2001).

The principal reasons for increasing the involvement of farmers in crop improvement programs can be outlined as follows:

(1) Different expectations - Different criteria-Addressing divers needs

It has been identified that end-users (stakeholders) participation is essential in developing varieties acceptable to them (i.e. farmer-preferred varieties), as their selection desires may be quite different to breeders' acceptability criteria (Soleri et al., 2000; Courtois et al, 2001). It is apparent that the farmers' selection criteria, largely based on environment factors, were quite different from those used by the formal breeding programs (Almekinders \& Louwaars, 1999). The diversity of needs of end-users in terms of food, beverages and other purposes highlights the fact that crop varieties often have multiple uses and can only be met by planting and maintaining a portfolio of crops and varieties (Atlin et al, 2001). Yield is not only defined by the grain, root or tuber production, but rather is an optimum function of production of different plant parts and uses, eg: young leaves as vegetables, grains for seed and food, dried stalks 
for fodder/animal feed etc), (Smale \& Bellon, 1999). The absence of these characteristics in varieties would lead to a rejection by small-scale farmers, even if they were high yielding. It appears that in these cases non-yield requirements are much more important than breeders anticipated, and hence be crucial for the adoption or rejection of new crop varieties (Ceccarelli, et al., 2001). This suggests that with the PPB approach breeders should be opened to unexpected and unplanned selection criteria.

Another aspect of PPB is that it provides a means of assessing "subjective traits" such as taste, aroma, appearance, texture and other characteristics that determine the suitability of a particular variety for culinary use. These traits are difficult to measure quantitatively, because they are a function of human perceptions. Identification and evaluation of subjective traits require close collaboration between plant breeders, social scientists, and farmers. Bellon (2001) has reviewed methods being developed by PPB practitioners to help in identifying and analyzing subjective traits.

\section{(2) Evaluation directly on target (production) environment}

A fundamental problem in plant breeding is the relationship between selection environment and target environment. The selection efficiency decreases as the selection environment becomes increasingly different from the target environment in terms of climate, soil and agronomic management etc. (Altin at al., 2001). When the selection environments are very different from the target environments, genotype - environment (GE) interaction usually gain importance because they change the relative ranking of the performances of breeding line (Banziger \& Cooper, 2001).

Falconer (1989) pointed out, direct selection in the target environment (or in an environment identical to the target) is always the most efficient. This can be achieved by selecting directly in each target environment, a type of selection defined by Simmonds, (1984) as decentralized selection. In PCI approach, GEI is greatly reduced since selection is always done in the target (production) environment. In this situation farmerdriven trials become important to develop cultivars to suit their needs since targeting heterogeneous and remote environments are difficult to address through a centralized formal breeding program (Almekinders \& Elings, 2001). Almekinders \& Elings, (1999) acknowledge GE interaction as an important issue and justification for PCI or PPB.

\section{(3) Supporting genetic diversity}

Today's agriculture is like a huge inverted pyramid. Globally it rests on a precariously narrow base. Less than $3 \%$ of the 250000 plant varieties available to agriculture are in use today (www.idrc.ca/seeds). The top-down system of agricultural research, where farmers are seen merely as recipients of research rather than as participants in it, has contributed to this dependence on a relatively few plant varieties. This trend and the increasing industrialization of agriculture are key factors that can be describe as "genetic erosion". However, the breeding model based on PPB methods encourages the maintenance of more diverse, locally adapted plant populations while promoting cultivar development (Ceccarelli et al., 1997; Joshi \& Witcombe, 1996). Witcombe et al (2001) discussed increasing genetic diversity by PVS in HPPSs too. 
(4) Speedy varietal adoption rate

Farmer participation in selection under their own environmental and agronomic conditions not only benefits the selection process but also speeds up the transfer and adoption of new varieties (Sperling, et al., 2001) without the involvement of complex mechanisms of variety release, extension services etc.. Although relatively little work has been done to document the speed of PPB compared to conventional breeding, recently evidence has started to emerge suggesting that PPB and PVS can lead to earlier adoption of new varieties (Joshi \& Witcombe, 1996; Ceccarelli, et al, 2001), with no major additional cost (Witcombe et al., 2003). According to Joshi et al., (2001) a rice variety breed by PPB showed steady increase in adoption and its spread commenced 5-6 years earlier than would have been the case in a conventional system.

(5) New varieties to grow with the existing package

The current agricultural production practices are highly dependent on expensive technology, and chemical inputs, and are simply not sustainable in the long run. However, any new agricultural technology should bring economic benefits to be adopted and accepted by farmer. In many instances although farmers are interested in using recommended inputs, these are often not available timely in sufficient quantity to meet their demands to realize the potential of the new variety (Courtois et al., 2001). With the outcome of the formal plant breeding products, farmers need to manage and control the environment to fit the genotype. In contrast, with PPB approach, the genotypes suitable are identified to fit existing environment rather than changing the environment to fit the genotype (Ceccarelli, et al.,
2001). Hence, in PPB approach, farmers are free to practice the same level of management in the trial as they had previously. The idea is that if the new variety developed through PPB can really provide better yield under the existing conditions, no additional expenditure need to be involved in adopting the new variety.

\section{Applications in modern plant breeding programs}

There is a belief that PPB is only feasible and work particularly well with subsistence farming with minor crops or under marginal conditions. However, there are contemporary evidences where PPB approach was found successful in applying in modern plant breeding programs too. A classic example of such participatory approach relates to Dutch potato breeding (Almekinders \& Louwaars, 1999). Breeders in potato breeding companies in the Netherlands, make the crosses between particular parents. Seeds of those crosses are given to farmers who perform the main selection work over a number of seasons. The farmers subsequently send the selected tubers back to the company for screening for pests and diseases, after which the farmer and breeder discuss the commercial prospects of the new selection. Promising varieties are registered and commercial revenues for the sale of the variety are shared between the farmer and the breeding company. PPB methods have been applied in Nepal for developing farmer-preferred rice varieties to HPPSs with few production constraints (Joshi, 2000). Hence, it is evident that the PPB is suitable not only for marginal but also for HPPSs and in modern plant breeding programs. 


\section{Criticism of the approach}

Despite the advantages discussed above, there are number of criticism proffered by scientists due to misconception of the approach (Witcombe, 1996), which are outlined below:

(1) Transfer of technology vs PCI

Some scientists claim that the participatory approaches by extension services are already being used. Although traditional extension methods can involve farmers, they often rely on demonstration of a few recommended varieties, grown by extension workers with a recommended package of practices. In contrast, with PCI, the main objective is not to transfer technology, but to empower farmers to learn, decide, adapt and do better with the assistance of scientists and extension agents rather than just testing the technology, which clarifies the distinction between participatory approach and transfer of technology (Witcombe, 1996).

\section{(2) Risk to farmer}

It is believed that PPB entails an unnecessary risk to the farmers. Breeders however, can help reducing the risk by providing farmers with advanced lines/breeding material. Farmers manage risk exceptionally well with the fewer resources they have. They never grow a new variety on a large area for the first time they cultivate it, unless they are sure of the performances of the new variety (Witcombe, 1996).

\section{(3) Reliability of results}

Some may question about the reliability of the results/ data generated from on-farm trials since breeders and varietal release committee would like to have data generated from statistically or formally designed evaluation trials. However, there are strategies adopted to overcome this issue, which include tools to aid discussions with farmers, modifications in field layout and design of on-farm testing and use of participatory evaluation methodologies (Almekinders \& Louwaars, 1999). During the testing period, farmers and breeders have the opportunity to discuss the merits of each material amongst themselves. Joint evaluation also involves the breeder/scientists visiting the farmers at different stages of crop development to discuss the performances hence, confirm the validity of the data and their reliability.

\section{(4) Cost effectiveness}

Another criticism over the approach is that the products of the PPB will not be cost effective as they are meant for niche environment hence, cannot be cultivated on a wide range of environment. Another issue is that without a formal release, the spread of varieties will be too limited to justify the cost, which is however not the case (Joshi, et al., 2001; Witcombe et al., 2003). Morris \& Bellon, (2004) suggest that return to investment will increase if use of PPB methods increases variety adoption level. Similarly, economic benefits will be created if use of PPB methods accelerates adoption of new varieties by reducing the time required to develop them (Pandey \& Rajataserrekul, 1999).

\section{Key challenges}

While the opportunity seems very promising, there are likely to be some bottlenecks in the PPB. The increase in participatory plant breeding and other collaborative programs involving farmers, their communities and formal sector scientists raise new questions and challenges for recognizing 
collaborative innovation in plant breeding:

\section{(1) Implications for institutions and technical challenges}

The institutional changes required include transformation of attitudes and behavior and linking informal with formal research and development. The difficulty of effecting major changes and reversals in large organizations underline the importance of seeing what changes of behaviors and attitudes are required, what institutional conditions are needed for them to be sustained and spread, and how these might be achieved considering the nature of the crop handled.

Another key challenge is to set up organizational models that allow the devolution of decision-making and onfarm testing to the local level. It is necessary to develop better strategies for supporting particularly, minor crops and those that do not come within the mandate of the formal research system.

\section{(2) Variety registration}

A clear constraint to PCI approach is the current regulatory framework that makes it practically impossible to gain official recognition of the suitability of a variety for cultivation. Regulatory authorities in many countries are still not willing to consider data generated using participatory methods when they evaluate varieties for registration and release (Morris \& Bellon, 2004). Results of on-farm trials are seldom taken into consideration in official varietal release procedure (Virk, 1998). In most countries, new plant varieties are approved for release only if they differ in some significant way from varieties that have already been released. " Subjective trait" performance data generated through PPB are usually not recognized in varietal approval guidelines (Morris \& Bellon, 2004), suggesting that existing regulatory procedures may have to undergo major revisions to accommodate benefits realized through PPB. Policy changes arising from such initiatives will take time, but the case will be strengthen by exposing more and more organization to the benefits of PPB/PVS and building their capacities to participation.

\section{(3) Intellectual property right (IPR)}

IPR and related issues are among the many challenges ahead for PPB. When the system alters to suit the needs for carrying out PCI, such as decentralization of testing to offstation sites, farm-trial design which the farmers are able to interpret for themselves, and which are conducted under "real farmer" input levels, raises the issue of IPR. If a farmer develops an improved variety in collaboration with the formal research system, who owns the right to that variety? who access and can distribute it? and how will the various benefits be shared? Currently in most countries, IPR systems offer little recognition to the role played by farmers in plant breeding (Morris \& Bellon, 2004). Some agencies believe that it is important to establish revised IPR regimes capable of equitably assigning credit to both farmer and the breeder (www.idrc.ca/seeds).

\section{(4) Economic challenges}

In a world of limited resources, research must be cost effective. Numerous case studies have estimated the returns to investment in conventional plant breeding programs, but the results tend to be specific to a particular location, organization, and crop (Morris \& Bellon, 2004; Pandey \& Rajataserrekul, 1999). Much less empirical work has been done to assess the returns to investment in PPB 
programs, which is not surprising that PPB methods are still new. Despite several technical reports on the success of PPB, more analysis is required to assess its economic impact. Economic evaluations of PPB continues to be limited by methodical problems, especially when it comes to estimating the benefits resulting from improvements of "subjective traits", one of the key advantages associated with PPB approach (Almekinders \& Elings, 2001). Hence, it has become necessary to generate improved knowledge about the economics of plant breeding so that the integration of formal and participatory plant breeding approaches could be based more explicitly on economic considerations.

\section{On the cutting edge - Biotechnology vs PPB}

It is worth noting that the potential extensive application of genetic engineering techniques does not eliminate the need for breeding programs to cope with GE interaction because almost no cultivar can assemble genes conferring superior performance in all environment types within a relatively large region (Witcombe, 1996). Also the possible selection for yield based on molecular markers may require preliminary definition of adaptation and yield stability targets, since a remarkable portion of useful markers are environment-specific (Hayes et al., 1993). In a wide adaptation prospect, marker-assisted selection (MAS) may prove distinctly less effective than multi-environment, phenotypic selection for yield in the presence of relatively large GE interaction (Cooper et al, 1999). The evidence presented indicates that these new approaches and methods involving participatory tools could serve the complex, divers and risk-prone agriculture.

\section{Success stories: Contemporary evidence}

Some preliminary reports indicated the positive impact of various forms of participatory approaches in increasing biodiversity and adoption of varieties both in favorable and less favorable environments (Witcombe, et al., 2001). Successful experiences which illustrated the potential of farmer participation in breeding include, incorporation of cold resistance in local rice varieties in Nepal, addressing a need of a group of farmers which was considered too small or too little importance for FPB to be addressed (Sthapit et al, 1996); experiences with pearl millet in Rajastan, India (Weltzien, et al., 1996) and the selection of bean varieties for complex and marginal conditions in Ruwanda (Sperling \& Scheidegger, 1995). Ceccarelli et al. (2000) demonstrated farmers' capacity in handling segregated population and in selecting high yielding barley entries under harsh and marginal environments compared to breeders in Syria. Likewise, in Jordan it was reported that under farmers' local conditions, the efficiency of farmers in identifying and selecting high yielding barley genotypes was found to be better than the efficiency of the plant breeders (Bishaw, 2004). In Colombia, a comparison has been made between farmers' and breeders' selection for cassava. It was concluded that breeders tend to select for yield and stress tolerance while farmers place greater emphasis on quality traits (Witcombe, 1996). Understanding the complexity of the local farming system, farmers' seed management and the value of characteristics of local materials was a key to the success of millet work in Rajastan (Weltzein, 2000). Significant genetic progress has been made for grain yield of wheat while providing 
sources of tolerance to the environmental stresses in the low input rain fed production system in Australia (Basford \& Cooper, 1998). Over 70 cases of PPB are documented, involving a range of crops and geographic regions (McGuire et al., 1999).

The few examples highlighted here and the other successful examples convinced that the PPB approaches were simple, effective and worthy of wide adaptation. Therefore, participatory approaches appeared to be useful in developing varieties that are more likely to adopted by farmers than conventional plant breeding for niche environments; i.e. "Adapting crops to environments and clients".

\section{CONCLUSIONS}

The aim of the PPB is to ensure that the research undertaken is relevant to the farmers' needs. The success stories of generating farmer-preferred varieties through PCI approaches have set a new pace in crop improvement programs worldwide. However, due to various challenges related to the approach, the potential applications and their implications are still to be explored. Although much of the emphasis has been placed on developing new varieties for marginal areas, PCI approach has proved its application in modern plant breeding programs too. Developments in this area also suggest that PCI could equally be applied to develop varieties for HPPSs. As the participatory method in crop improvement is an emerging new concept, some criticism over the approach and some controversial arguments still exist. While the opportunity seems very promising, this approach in plant breeding raises new questions and challenges in relation to institution and economical aspects. The prediction is that PCI could offer tremendous opportunity to increase agricultural production, perhaps not less than that offered by biotechnology, to improve the food security.

\section{References}

Almekinders, C.J.M., and A. Elings, (1999). Collaboration between breeders and farmers in different stages of the crop development process - Discussion paper, Society of American Anthropology - Session PPB, April 22, 1999, Tuscon, Arizona.

Almekinders, C.J.M., and A. Elings, (2001). Collaboration of farmers and breeders: Participatory crop improvement in perspective, Euphytica, 122: 425-438.

Almekinders, C., and N. Louwaars, (1999). Farmers' seed production: New approaches and practices, Intermediate Technology Publications, London, U.K.

Altin. G.N., M. Cooper and A. Bjornstad, (2001). A comparison of formal and participatory breeding approaches using selection theory, Euphytica, 122: 463475.

Banziger M. and M. Cooper, (2001). Breeding for low input conditions and consequences for participatory plant breeding: examples from tropical maize and wheat, Euphytica, 122: 503-519.

Basford, K.E. and M. Cooper, (1998). Genotype x Environment interaction and some consideration of their implications for wheat breeding in Australia, Australian J Agric. Res., 49: 153- 174. 
Bellon, M.R. (2001). Participatory research methods for technology evalustion: A manual for scientists working with farmers. CIMMYT, Mexico.

Bishaw, Z. (2004). Wheat and Barley seed systems in Ethiopia and Syria. Wageningen, The Netherlands.

Ceccarelli, S., E. Bailey, S. Grando andR. Tutwiler,(1997). Decentralisedparticipatory plant breeding: a link between formal plant breeding and small farmers. CGIAR System wide Project, Cali, Columbia, pp 65-74.

Ceccarelli, S., S. Grando, E. Bailey, A. Amir, M. El-Felah, F. Nassii, S. Rezgui and A. Yahyoui, (2001). Farmer participation in barley breeding in Syria, Morocco and Tunisia, Euphytica, 122: 521-536.

Ceccarelli, S., S. Grando, R. Tutwiler, J. Baha. A.M. Martini, H. Salahieh, A. Goodchild and M. Michael, (2000). A methodological study on participatory barley breeding. I. Selection phase, Euphytica, 111: 91-104.

Conway, G. (1998). The doubly green revolution: Food for all in $21^{\text {st }}$ century. London, Penguin.

Cooper, M., D.W. Podlich, N.W. Jenson, S.C. Chapman and G.L. Hammer, (1999). Modeling plant breeding programs, Trends in Agronomy, 2: 33-64.

Courtois, B, B. Bartholome, D. Choudhary, G, McLaren, C.H. Misra, (2001). Comparing farmers and breeders ranking in varietal selection for low input environment; a case study of rain fed rice in eastern India, Eupytica, 122: 537555.

Elings, A., C.J.M. Almekinders and P. Stam (2001). Introduction: Why focus the thinking on participatory plant breeding, Euphytica, 122: 423-424.

Falconer, D.S. (1989). Introduction to quantitative genetics. $3^{\text {rd }}$ edition, Longma, London.

FAO (1996). Food requirement and population growth. Technical Background document, FAO Corporate Document Repository. (www.fao.org/docrep).

Hayes, P.M., B.H. Liu, S.J. Knapp, F. Chen, B. Jones, T. Blake, J. Franckowiak, (1993). Quantitative trait locus effects and environmental interaction in a sample of North American barley germplasm, Theory and Applied Genetics, 87: 392- 401.

Joshi, K.D., (2000). Strengthening the farmers' seed systems in Nepal, Biotechnology \& Development Monitor, 42: 15-17.

Joshi, K.D., B.R. Sthapit and J.R. Witcombe (2001). How narrowly adopted are the products of decentralized breeding? The spread of rice varieties from PPB program in Nepal, Euphytica, 122: 589 -597.

Joshi, A. and J.R. Witcombe, (1996). Farmer participatory crop improvement II. Participatory varietal selection; a case study in India, Experimental Agriculture, 32: 461-477.

McGuire, S., G. Manicad and L. Sperling, (1999). A global analysis of issues and current experiences, CGIAR Systemwide program on participatory research, Working Document No. 2, March 1999, Cali, Columbia.

Morris, M.L. and Bellon, M.R. (2004). Participatory plant breeding research: Opportunities and Challenges for the international crop improvement system, Euphytica 136: $21-35$.

Pandey, S. and S. Rajataserrekul, (1999). Economics of plant breeding: the value of shorter breeding cycles for rice in Northeast Thailand, Field Crop Research, 64: 187-197. 
Pinstrup-Andersen, P., R. Pandya-Lorch and M.W. Rosegrant, (1999). World food prospects: Critical issues for the early twenty first century. 2020 vision, Food Policy Report, October 1999. International Food Policy Research Institute, Washington D.C.

Simmonds, N.W. (1984). Principles of crop improvement. Longman, London \& New York. pp 408.

Singh, R.B., (2000). Environmental consequences of agricultural development: a case study from the green revolution in State of Haryana, India. Agricultural Ecosystems and Environment, 82: 97-103.

Smale, M. and M.R.Bellon, (1999). A conceptual framework for valuing on-farm genetic resources. Agrobiodiversity: Characterization, Utilization and Management, Wallingford, CABI publishing, pp 387-408.

Soleri D., S.E. Smith and D.A. Cleveland, (2000). Evaluating the potential for farmer and plant breeder collaboration: A case study of farmer maize selection in Oaxaca, Mexico, Euphytica, 116: 41-57.

Sperling, L., J.A. Ashby, M.E. Smith, E. Weltzien, and S. McGuire, (2001). A framework for analyzing participatory plant breeding approaches and results, Euphytica, 122: 439-450.

Sthapit, B.R., K.D. Joshi and J.R. Witcombe, (1996). Farmer participatory crop improvements. III. Farmer participatory plant breeding in Nepal. Experimental Agriculture, 32: 479-496.

Virk, D.S. (1998). The regulatory framework for varietal testing and release in India. In: D.S. Virk and J. Farington (Eds.) Seeds of choice. Making the most of new varieties for small farmers. Pp. 69-84, Intermediate Technology Publication, London.

Weltzien, E., (2000). Supporting farmers' genetic resource management: Experiences with pearl millet in India, In: C. Almekinders \& W. de Boef (eds.), Encouraging Diversity. Pp 189-193. Intermediate Technology Publications, London.

Weltzien, E., M.E. Smith, L.S. Meitzner and L. Sperling, (2000). Technical and institutional issues in participatory plant breeding - from the perspective of formal plant breeding. An analysis of issues, results, and current experiences. CGIAR Systemwide program on participatory research, Working Document 3.

Weltzien, E., M.L. Whitaker and M. Dhamotharan, (1996). Diagnostic methods for pearl millet with farmers in Rajasthan. Proc. Of Enhancing and Maintaining genetic resources on-farm, 19-21 June, 1995, New Delhi, India, pp127-139.

Witcombe, J.R., (1996). Participatory approaches to plant breeding and selection, Biotechnology and Development Monitor, 29: p.26.

Witcombe,J.R., K.D. Joshi, R.B. Rana and D.S. Virk, (2001). Increasing genetic diversity by participatory varietal selection in high potential production systems in Nepal and India, Euphytica, 122: 575-588.

Witcombe, J.R., A. Joshi, K.D. Joshi and B.R. Sthapit, (1996). Farmer participatory crop improvement. I. Varietal selection and breeding methods and their impact on biodiversity, Experimental Agriculture 32: 445-460.

Witcombe, J.R., A. Joshi and G.N. Goyal, (2003). Participatory plant breeding in maize: a case study from Gujarat, India, Euphytica, 130: 413-422. 